Ruiz Bañón, María Luz.

Investigadora predoctoral Fundación Séneca, Universidad de Murcia, Departamento de Bellas Artes, Grupo de Investigación Estudios Visuales: Imágenes, Textos, Contextos.

\title{
Temporalidad y espacialidad desbordada en la obra de Jesús Segura
}

\section{Temporality and spatiality overflowed in the artwork of Jesús Segura}

TIPO DE TRABAJO: Comunicación virtual.

\section{PALABRAS CLAVE}

Jesús Segura, temporalidad, espacialidad, contexto, videoarte, arte contemporáneo.

KEY WORDS

Jesus Segura, temporality, spatiality, context, video art, contemporary art.

RESUMEN

La presente comunicación analiza las estrategias narrativas presentes en la producción artística del artista español Jesús Segura, centrándose en el análisis de su obra audiovisual, performativa, instalativa y fotográfica incluida en la exposición antológica "Time Lag", llevada a cabo en el Museo de Arte Moderno de la Región de Murcia (MURAM) entre diciembre de 2018 y marzo de 2019 . La intención es reflejar y debatir sobre las distintas temporalidades presentes en su obra artística, exponiendo las conexiones entre las estrategias de reconstrucción espacio-temporales utilizadas y la crítica ideológica sociopolítica que el artista lleva a cabo a través de ella. Por medio de una metodología de investigación cualitativa inductiva, basada en la observación directa, la entrevista y la revisión bibliográfica, se busca determinar y acotar el uso de las distintas temporalidades críticas y espacialidades desbordadas a lo largo de su producción, analizando el uso de recursos como la anacronía o la heterocronía para producir la colisión del espacio y el tiempo, que se ven alterados debido a sus prácticas procesuales. Todas estas estrategias narrativas nos van a llevar a clasificar sus principales obras dentro de la categoría establecida por el propio artista de espacialidades desbordadas o alteradas.

\section{ABSTRACT}

This paper analyses the narrative strategies present in the artistic production of the Spanish artist Jesús Segura, focusing on the analysis of his audiovisual, performative, installation and photographic work included in the anthological exhibition "Time Lag", held at the Museum of Modern Art of the Region of Murcia (MURAM) between December 2018 and March 2019. The intention is to reflect and debate on the different temporalities present in his artistic work, exposing the connections between the strategies of space-time reconstruction used and the socio-political ideological criticism that the artist carries out through it. By means of an inductive qualitative research methodology, based on direct observation, interview and bibliographic review, the aim is to determine and limit the use of the different critical temporalities and overflowing spatialities throughout their production, analysing the use of resources such as anachronism or heterochrony to produce the collision of space and time, which are altered due to their procedural practices. All these narrative strategies will lead us to classify his main works within the category established by the artist himself of overflowing or altered spatialities. 


\section{INTRODUCCIÓN}

Para la realización de esta comunicación se ha tomado como caso de estudio la exposición antológica del artista español Jesús Segura (Cuenca, 1967) titulada Time Lag. La exhibición, organizada por la Comunidad Autónoma de la Región de Murcia a través de su Consejería de Turismo, Cultura y Medio Ambiente y el Museo de Arte Moderno de la Región de Murcia (MURAM), fue comisariada por el crítico de arte, docente e investigador del Departamento de Historia del arte de la Universidad de Murcia Miguel Ángel Hernández Navarro, el director artístico del museo Juan García Sandoval y el propio artista. Ubicada en dicho museo, la muestra se desarrolló entre el 14 de diciembre de 2018 y el 10 de marzo de 2019, y en ella se pudo contemplar la producción artística fotográfica y audiovisual más relevante de Jesús Segura realizada a lo largo de las dos últimas décadas, entre 1999 y 2012, ofreciendo al espectador una visión global de su trabajo.

La muestra ha proporcionado la oportunidad de comprobar como dentro de la extensa obra del artista es constante el cuestionamiento y la reactualización de la noción espacio-temporal mediante el análisis crítico e histórico de la imagen. En ella podemos apreciar un uso recurrente de diferentes estrategias de reconstrucción espacial y delimitación de las cronologías presentes en la imagen para poner en cuestión la noción lineal del espacio-tiempo. Segura genera, a través de la utilización simultanea de diferentes formatos como la fotografía, el vídeo, la acción performativa o la instalación, lo que define como "espacialidades desbordadas" o alteradas (Segura-Cabañero y Simó-Mulet, 2017). Nos referimos a las producciones artísticas contemporáneas que contribuyen a la ruptura de la organización espacio temporal heredada del modernismo por medio de las alteraciones recurrentes de la temporalidad, como el uso de la anacronía o la heterocronía, y que constituyen una modalidad de resistencia ante la concepción narrativa lineal del tiempo y la historia (Segura-Caballero, 2018). En la era de la globalización y la inmediatez, en este contexto donde los límites entre el espacio-tiempo se han diluido gracias al desarrollo tecnológico y la mejora de las comunicaciones permitiéndonos estar en conexión continua con cualquier parte del mundo, podemos decir que nuestra realidad presente va a estar compuesta por "una suma de tiempos en movimiento continuo, de pasados que no acaban de irse y de futuros que nunca llegaron, de saltos y discontinuidades" (Hernández-Navarro, 2014, p.190). La intención del uso de estas estrategias narrativas de reconstrucción espaciotemporales dentro del lenguaje del arte contemporáneo responde a la necesidad de poner en cuestión tanto los usos sociales que se le presumen a estos espacios apostando "por un sentido trastornado del lugar, el espacio, el tiempo y el contexto" (Segura-Caballero y Simó-Mulet, 2017, p.224), como el régimen temporal hegemónico del presente. De acuerdo con ambos autores, en función de la estrategia empleada, estos espacios pueden ser clasificados como anacrónicos, heterocrónicos o invasivos.

En primer lugar, podemos considerar como espacio anacrónico a aquel en "el que se desarrollan intervenciones artísticas que decodifican la obsolescencia de un espacio y su estatuto mutable, para articular modelos espacio-temporales que dialogan entre pasado, presente y futuros posibles, reescribiendo una nueva funcionalidad histórica del lugar" (Segura-Caballero y Simó-Mulet, 2017, p.224), replanteando a través de la práctica artística el concepto de temporalidad mediante la inversión o alteración del tiempo y la historia de un espacio, rompiendo de ese modo con la secuencia temporal lógica.

Por otro lado, el espacio heterocrónico es aquel que "alberga prácticas artísticas que modifican el estatuto espacial del lugar, incorporando una hibridación de lo local y lo global. Estos espacios despliegan temporalidades diversas que colisionan entre si para articular una geolocalización que permita definir sus nuevos usos sociales" (Segura y Simó, 2017, p.226). Siguiendo a Keith Moxey (2013) podemos determinar que en la actualidad el tiempo histórico ha dejado de ser considerado como algo universal y monocrónico, para pasar a ser definido como un tiempo heterocrónico que "no se mueve a la misma velocidad en espacios diferentes" (p.1). Estos espacios, al verse sometidos al flujo migratorio de la globalización, reaccionan desplegando una temporalidad multirítmica. A través de ellos el artista se interroga sobre la vida cotidiana de las ciudades y la multitud que vive en ellas. Son lugares que nos van a mostrar una realidad espacio temporal en la que el tiempo experiencial no resulta homogéneo respecto a todas las personas, ya que individualmente los humanos somos capaces de experimentar y sentir, de forma simultánea, diferentes ritmos temporales dentro de un tramo común de tiempo. En este sentido, Mieke Bal (2011) establece que esta experiencia multirítmica en la que se desarrolla nuestra vida, y donde habitualmente nos desenvolvemos en modo multiárea-multitemporal, es lo que define el concepto de heterocronía.

Por último, consideraremos como espacios invasivos o subalternos a aquellos que plantean "intervenciones artísticas que cuestionan y transforman la identidad de un lugar mediante un reprocesamiento de sus elementos puestos en común" (Segura y Simó, 2017, p.229), articulando para ello diferentes temporalidades estratificadas y vinculadas entre si que llevan al espacio a alcanzar una entidad colectiva, y que ponen a prueba nuestra relación con el espacio, el tiempo y la memoria. De este modo, "al criticar la producción del sujeto colonial, este lugar inefable y no-trascendental ('histórico') es llenado por el sujeto subalterno" (Spivak, 1998, p.26), que recupera su capacidad de hablar y narrar enfrentándose a sus propios condicionamientos.

Teniendo en cuenta las anteriores clasificaciones y sus características, el objetivo general de esta comunicación se encamina a la delimitación y análisis de las diferentes estrategias de reconstrucción espacio-temporal utilizadas por Segura en las principales obras exhibidas en dicha muestra, así como a la observación de las conexiones que se establecen entre estos recursos temporales y su crítica ideológica sociopolítica. Para el desarrollo de este objetivo general se marcaron a su vez unos objetivos específicos. En primer lugar, 
obtener una descripción que refleje el uso de las distintas temporalidades críticas y espacialidades desbordadas que aparecen a lo largo de la producción artística de Segura dentro de su contexto visual y cultural para el cuestionamiento y la reactualización de la noción espacio-temporal. Por otro lado, realizar de forma simultánea un análisis de la evolución, alternancia y modificación de estas estas estrategias a través del tiempo. Para ello se parte de la hipótesis de que su inquietud por temas como la temporalidad, la espacialidad o el contexto, está presente en todo su universo, por lo que su obra artística puede incluirse dentro de la categoría de "espacialidades desbordadas".

Se trata en última instancia, de determinar en qué modo la obra artística de Jesús Segura resulta ser es una muestra de cómo las imágenes se convierten en construcciones culturales de cada uno de los contextos determinados donde surgen, de cómo el artista articula y configura la imagen contemporánea afectada por las nuevas temporalidades, y de determinar cuál es de la relevancia de estas prácticas de ver y mostrar dentro de la nueva cultura visual que nos llevan a repensar la linealidad de la narrativa espaciotemporal haciéndonos modificar nuestro modo de percibir y habitar el mundo.

\section{METODOLOGÍA}

Los procedimientos utilizados para dar respuesta a los objetivos planteados en este trabajo se han centrado en el desarrollo de una metodología de investigación cualitativa inductiva. Para ello se han utilizado diferentes técnicas como la observación directa de la obra del artista exhibida dentro de la exposición antológica Time Lag, que nos ha proporcionado diferentes registros observacionales narrativos y una visión global de la obra de Jesús Segura. Para evitar el inconveniente de la subjetividad del observador, esta técnica se ha complementado tanto con la realización de una visita guiada por el propio artista, como con una posterior entrevista semiestructurada con él. Ambas técnicas, proporcionaron la oportunidad única de interaccionar con el entrevistado y resolver directamente todas las cuestiones que se nos plantearon en nuestra investigación, obteniendo una visión clara del propio artista sobre su obra, objetivos y razones de su estética y formato. Además, se realizó en paralelo una investigación exploratoria a través de la revisión bibliográfica especializada de obra de historiadores y críticos de arte acreditados en la materia.

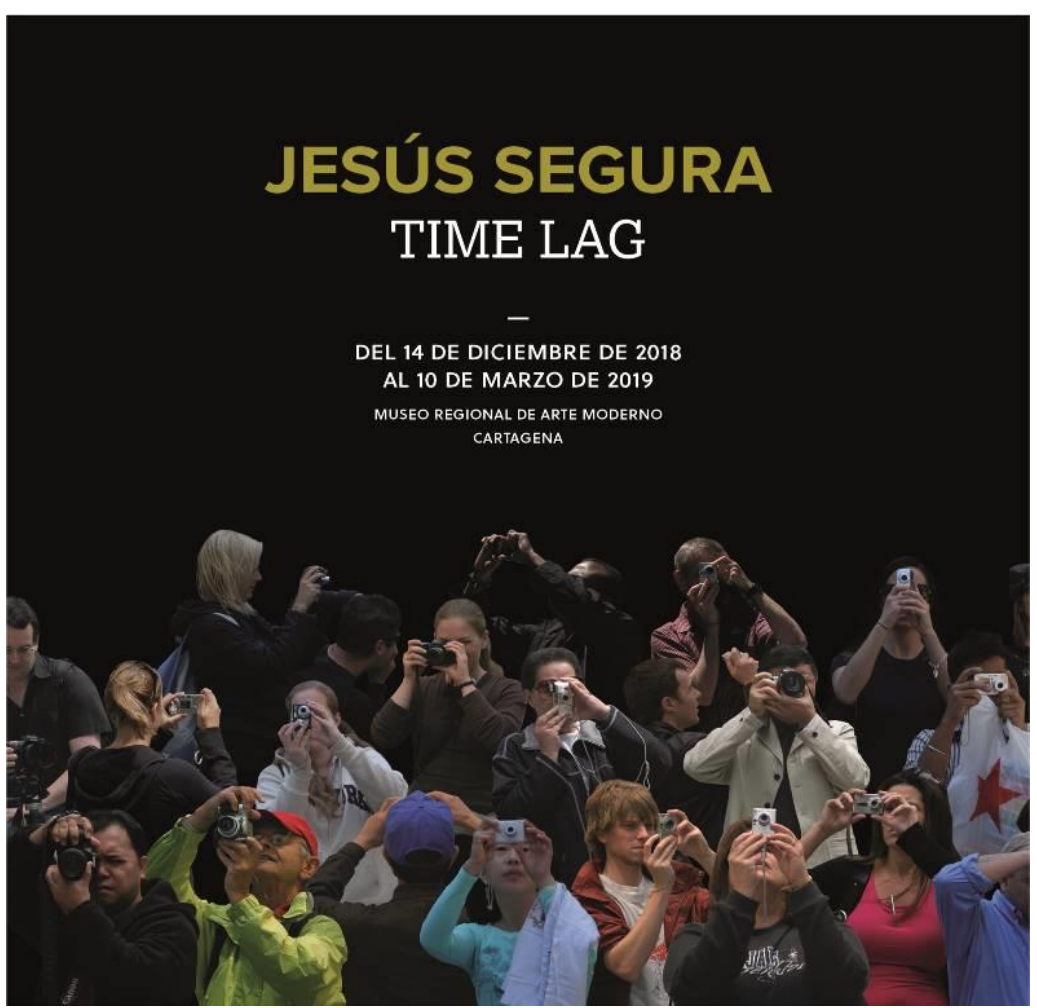

Figura 1: Cartel de la exposición “Time Lag” de Jesús Segura, 2018-2019. Fotografía del autor. 


\section{DESARROLLO}

En Time Lag, el propio diseño expositivo de la muestra resulta ser ya una declaración de intenciones del artista. Segura propone para esta muestra antológica un recorrido anacrónico y no lineal, donde obras de sus primeros años de producción conviven con otras recientes, rompiendo de este modo con una posible secuencia o lógica temporal clásica del modernismo. Nada más traspasar el umbral del museo nos recibe la grandiosa e impactante obra fotográfica, "Paisaje II" realizada en 1999, que capta en seguida la atención del público que visita la muestra. Un paisaje que nos muestra una realidad transversal, cuyo aspecto fantasmal y apocalíptico remite al estado interior visualizándose como un paisaje metafísico. En él, de forma reiterativa y clonada, el artista introduce unos remolinos de aire y tierra que nos trasladan a una nueva realidad espacio temporal. Un campo árido y yermo, en espera de lluvia y cosecha, que nos habla de desertización y mala gestión sociopolítica. Un paisaje de liberación estereofónico que logra introducir elementos emocionales en la imagen confiriendo al paisaje el estatus de ser vivo dotándole de voz.

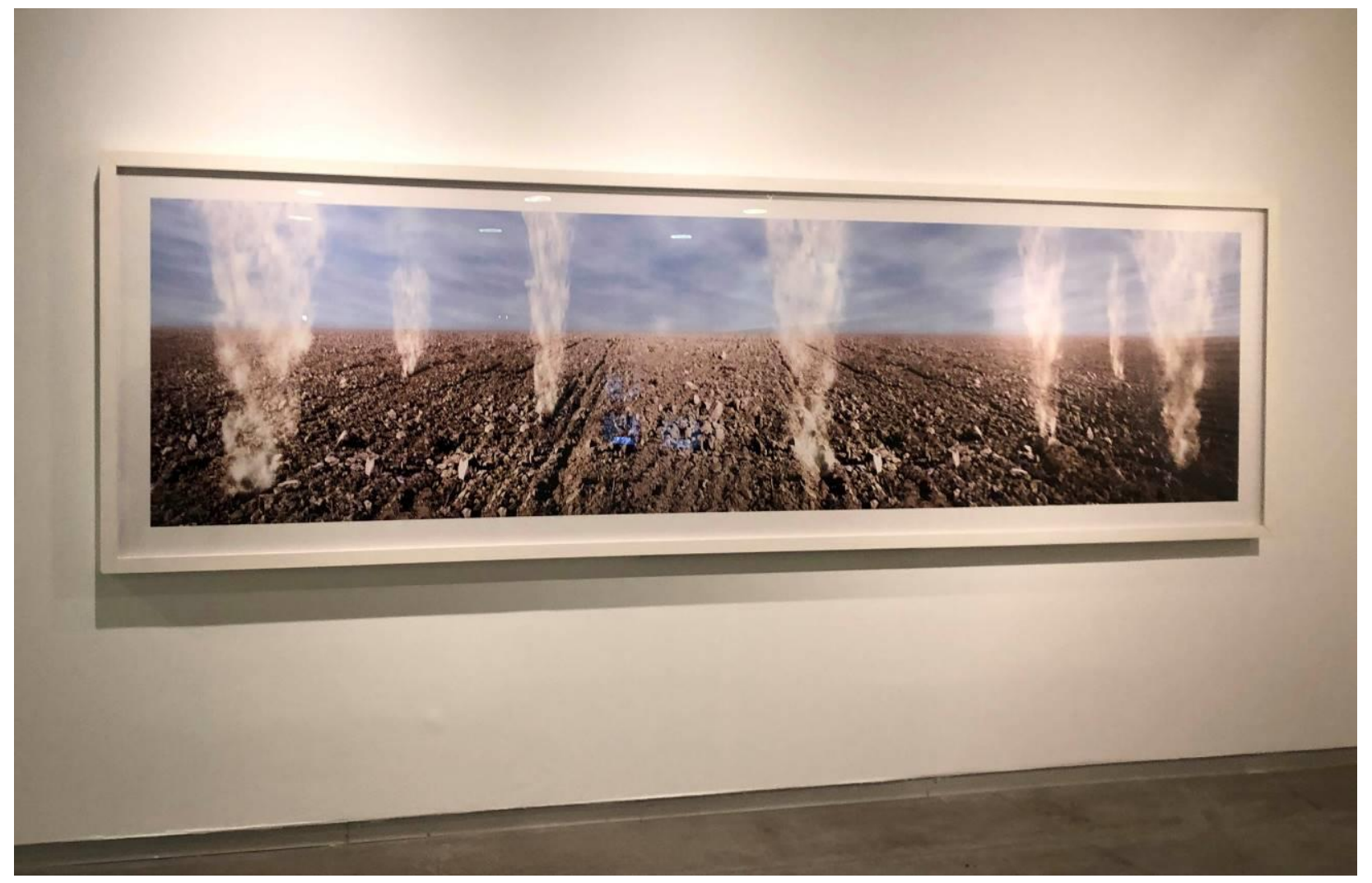

Figura 2: Fotografía cibachrome y metacrilato. "Paisaje II", Jesús Segura, 1999. Tamaño 90 x 490 cm. Fotografía del autor.

A su derecha, cuatro monitores nos muestran de forma simultánea escenas de la serie audiovisual "Lugares" realizada entre 1999 y 2000. La acumulación de estos monitores potencia la manera de entender esta pieza cobrando más fuerza narrativa ante la imposibilidad de visualizar lo que acontece en todas las pantallas al mismo tiempo por un problema de hipervisualidad o limitación en nuestra capacidad de percepción. Nuestra vista va discriminando dónde centrar la mirada, por lo que se produce ese efecto de paisaje multitemporal y heterocrónico de describe Jesús Segura en sus textos. La obra genera también gran tensión heterotópica al yuxtaponer en un mismo espacio imágenes ambivalentes cuya veracidad resulta en muchos casos cuestionable para el espectador. Para Enric Mira (2018), en este caso, "la preocupación por el tiempo expandido de las imágenes se alterna con una deconstrucción del espacio de representación" (p.95) "donde los muros son metáforas de lo humano y los encuentros orillan el abismo insondable del silencio" (p.98). Los videos, de diferentes duraciones, son reproducidos en bucle infinito, por lo que la experiencia de cada espectador va a estar condicionada por el azar que recodifica la imagen a través de una suerte de recombinaciones múltiples, produciendo una diversificación de los significados de la obra. 


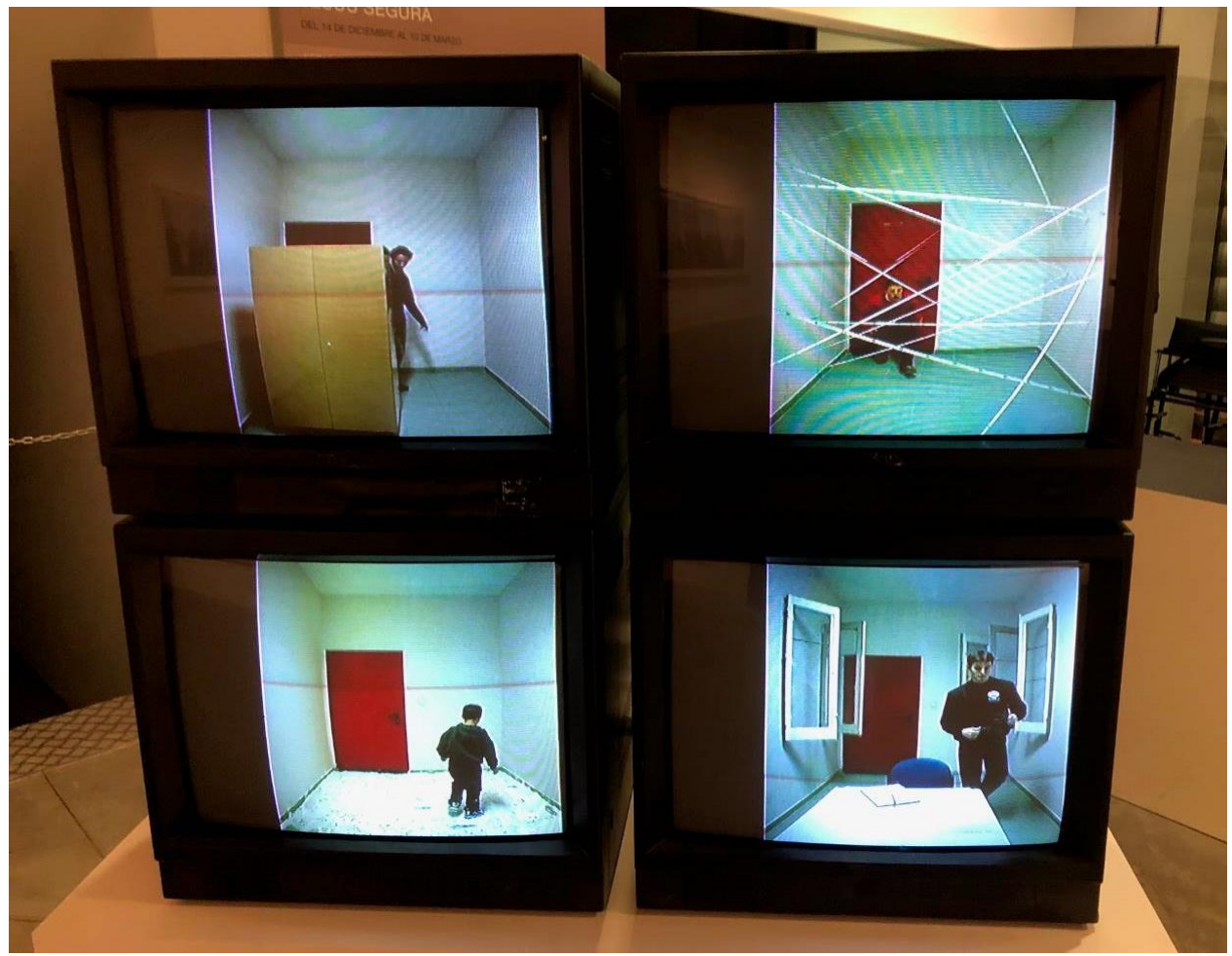

Figura 3: Video 4 canales. "Serie Lugares". "Armario", "Ventanas", "Cintas" y “Huellas". Jesús Segura, 1999/2000. Duraciones variadas (entre 2:15 y 3:10 minutos). Fotografía del autor.

"Summi Red" (2002) es la siguiente obra audiovisual que se cruza en nuestro recorrido. Una pequeña proyección circular que el artista ha ubicado en el suelo, bajo el tramo de subida de una escalera de cristal. La obra nos habla de lo subalterno generando un espacio invasivo que otorga voz a los desconectados y oprimidos que viven fuera de los límites del circuito de la sociedad capitalista. En este caso, los talleres clandestinos de producción en Chinatown en Nueva York. La proyección no se realiza de forma frontal, ni se muestra de forma directa, sino que el artista busca generar una imagen representativa de lo furtivo, de lo encubierto para realizar una sutil y velada crítica sociopolítica.
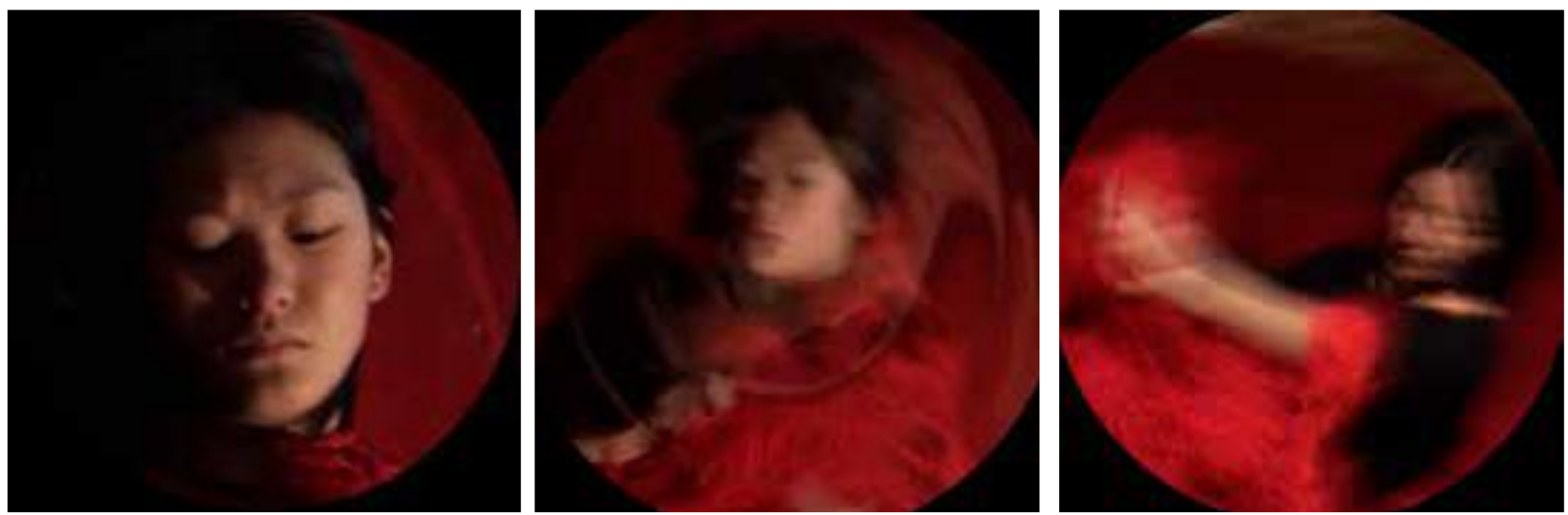

Figura 4: Video monocanal. Fotogramas “Summi Red”, Jesús Segura, 2002. Duración 1:42 min. Fotografía del autor.

Dentro de una pequeña sala negra de proyección se reproduce el video titulado "Slave" (2001), un videodocumento que recoge la performance realizada por Segura en las calles de una ciudad cualquiera. Un montón de flores forman sobre la transitada acera la palabra esclavo en inglés, slave. Al paso de la gente, el mensaje empieza a deformarse hasta llegar a desaparecer. Una idea performativa que rompe con la idea de lo socialmente impuesto y se deja afectar por el azar fluyendo como una obra dadaísta cercana al Fluxus. Con todo ello se genera una suerte de denuncia por la igualdad de los derechos laborales, que se ve reforzada y actualizada 
por la interacción del espectador con dicha obra, ya que se pone en diálogo el presente, pasado y futuro. Segura rompe, con la edición de esta performance, con la narrativa lineal espacio-temporal generando elipsis temporales a través de la eliminación de algunos fotogramas, y tiempos alterados mediante la aceleración de otros que hacen que los viandantes circulen como motocicletas al ritmo frenético que marca el efervescente tráfico de la ciudad.

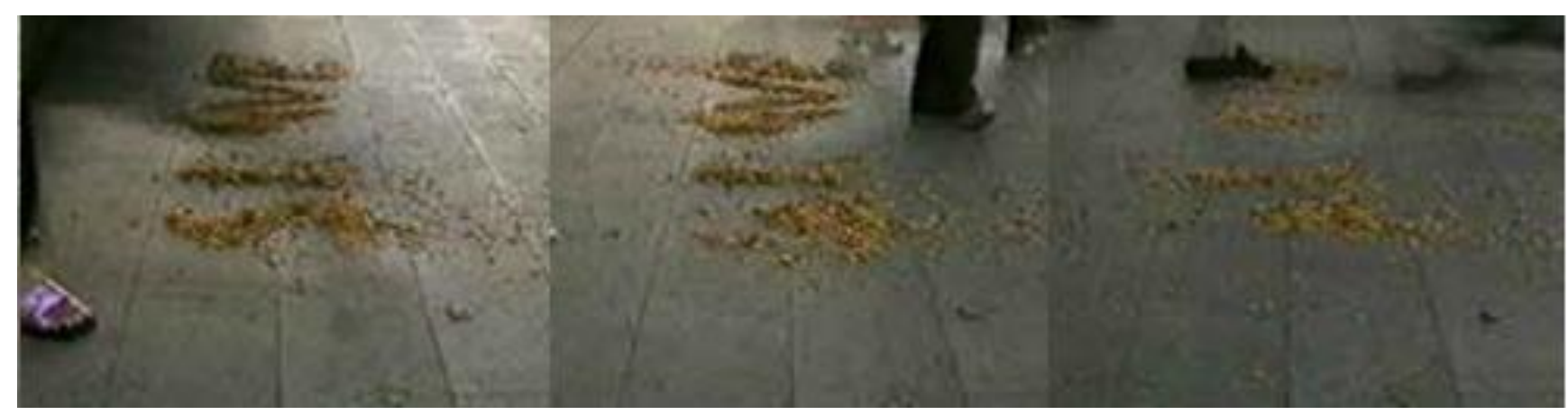

Figura 5: Video monocanal. Fotogramas de "Slave", Jesús Segura, 2001. Duración 6:05 min. Fotografía del autor.

"Ritual animal" (2004) sucede en la pantalla a la anterior obra. Se trata de un video monocanal que representa una acción performativa donde podemos contemplar una autorepresentación del artista. Un ser, mezcla entre animal y humano, un hibrido antropomorfo que se mueve torpemente en la noche arrastrándose a cuatro patas por encima de un montón de hojas secas. Una imagen fantasmal e inquietante, en un proceso de vuelta a lo primitivo, que nos muestra el proceso de búsqueda del yo del propio artista. El artista genera con ello una espacialidad alterada a través de una imagen animal-humano que se separa y fusiona repetidas veces por medio de capas, discontinuidades y opacidades que crean realidades paralelas y alternativas.

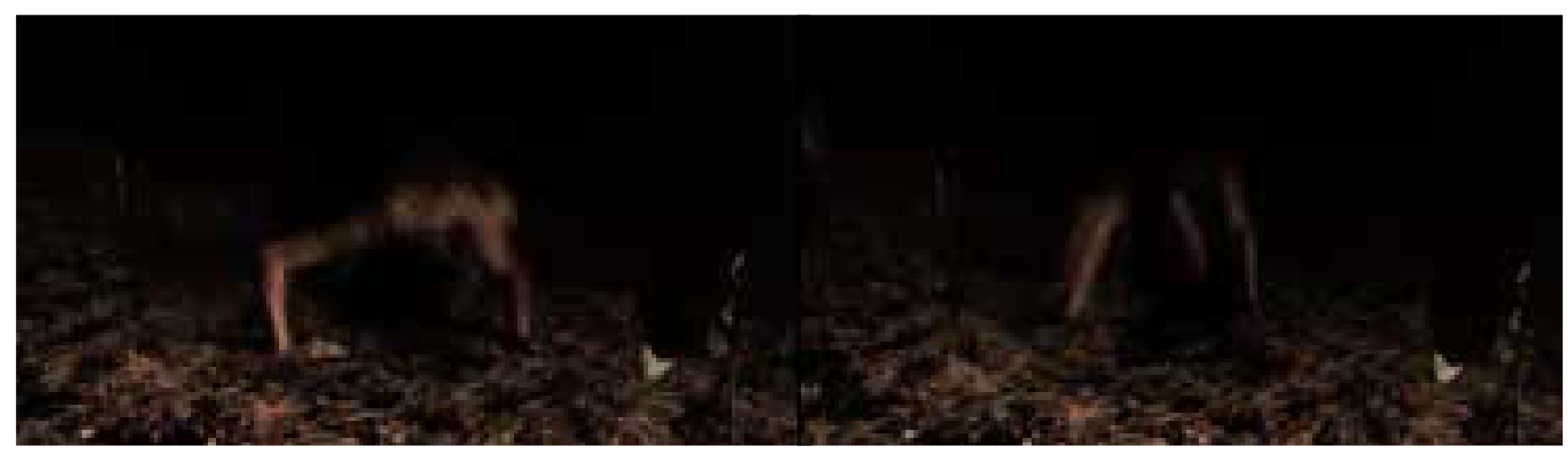

Figura 6: Video monocanal. Fotogramas de “Ritual Animal”, Jesús Segura, 2004. Duración 2:27 min. Fotografía del autor.

En otra sala nos encontramos con "Tránsitos" (1998), una instalación fotográfica diseñada para abrir los sistemas perceptivos del espectador. En ella el público se coloca el en el centro de la sala de forma que queda rodeado de fotografías de grandes dimensiones que forman un juego-laberinto de espejos. Una realidad de nuevo ficticia pero posible, que nos introduce en el contexto de un paisaje de imágenes reflejadas que parecen devolvernos la imagen del otro a modo de eco imposible, del yo diverso. Al mismo tiempo la instalación nos plantea una narrativa de tiempo-espacio alterada que nos devuelve a otros momentos anteriores o posteriores. De nuevo se funde el ahora, el pasado y el futuro, en una imagen confusa e irreal, donde parece que todo el espacio se abre a través de la falsa la percepción del sistema de espejo, generando la ilusoria expectativa en el publico de verse incluido en la obra a través su propio reflejo. 


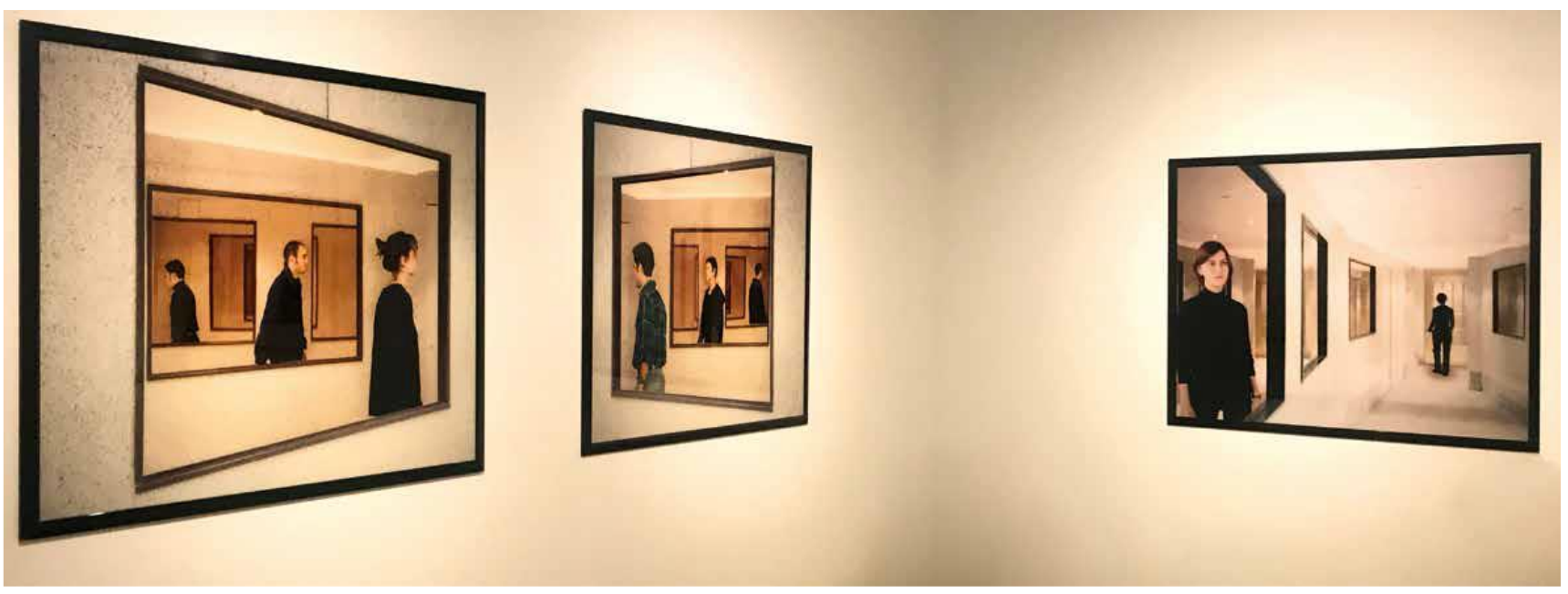

Figura 7: Fotografía cibachrome, metacrilato y moldura. "Tránsitos", Jesús Segura, 1998. Tamaño de c.u. 120 x 154 cm. Instalación fotográfica de 6 piezas. Fotografía del autor.

"Transported" (2008) constituye un espacio que es ficticio, pero que podía ser real. Inspirado en los dibujos de las "Prisiones imaginarias" de Giovanni Battista Piranesi con sus escalinatas que no llevan a ninguna parte, e incluso en los paisajes metafísicos de De Chirico, los personajes de esta performance se mueven a distintos ritmos al compás del sonido de maquinaria de producción. Segura construye una escenografía urbana de carácter ambiguo y voluntariamente desorientadora, que establece nuevas relaciones entre lo natural y lo artificial. Una hibridación de formatos, temporalidades y escalas que generan un lugar imaginado, inquietante y sugerente, que engaña a nuestros sentidos. El artista juega con el adelante-atrás, arriba-abajo, izquierda-derecha, rápido-lento, e incluso con los planos cambiados, para generar un espacio posible pero ficticio que nos dirige al mundo onírico del subconsciente. Sueño o realidad construye este universo metafísico conformado como un paisaje heterocrónico que no tiene principio ni fin. Al igual que ocurre en la obra de Douglas Gordon, "la incorporación de recursos técnicos que aceleran, interrumpen, desnaturalizan y trastornan los ritmos temporales cotidianos para producir perturbaciones en la percepción de las imágenes es fruto de un proceso crítico llevado a cabo por el artista" (Segura-Cabañero, 2013, p.57).

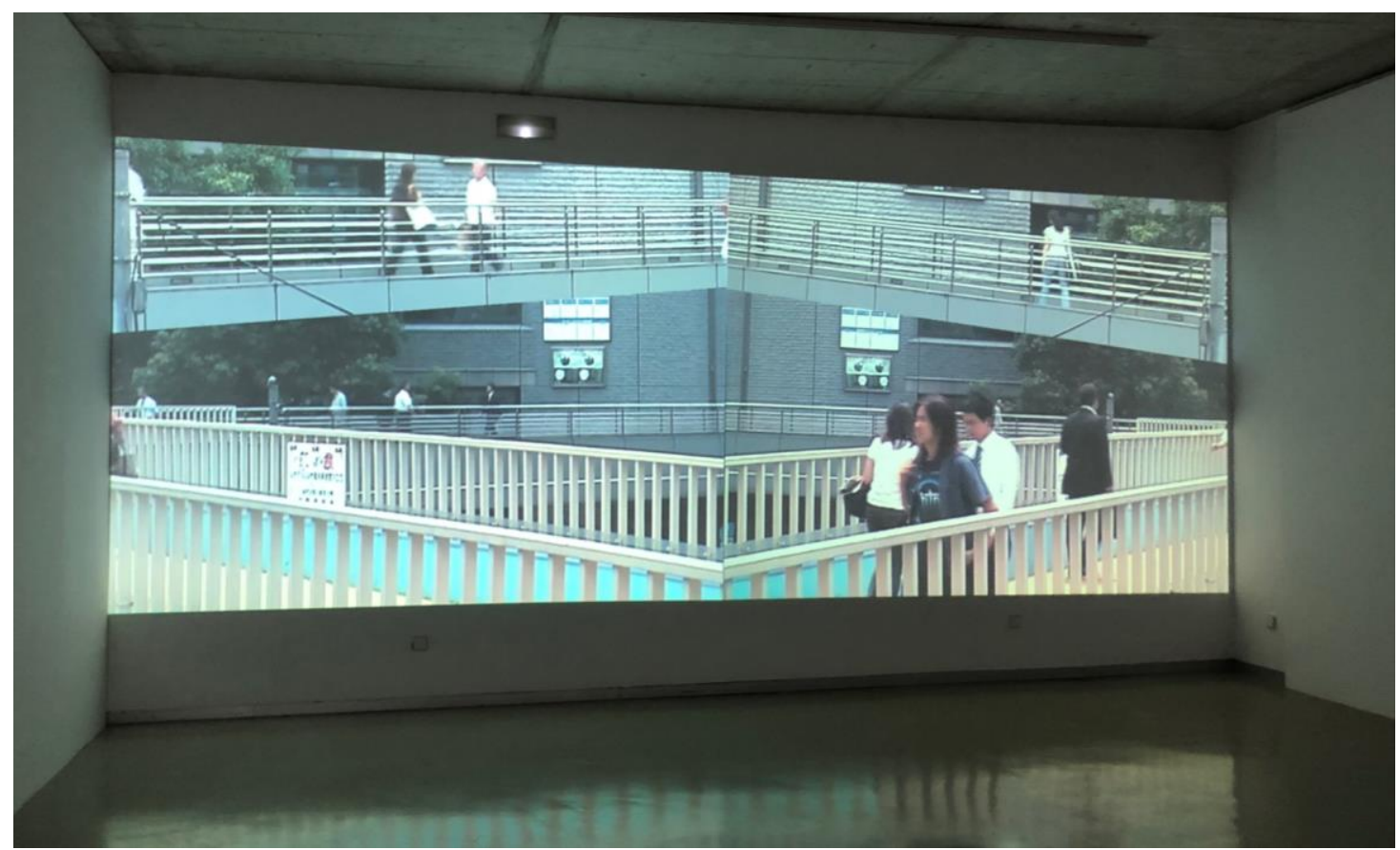

Figura 8: Videoinstalación a dos canales. "Transported”, Jesús Segura, 2008. Duración 4:46 min 
Por último, en obras como "(Des)conectados" (2007) o "Transported" (2008), el artista muestra espacios habitado por sujetos alienados que transitan los espacios en un bucle continuo sin conciencia de este movimiento, sin llegar a discernir su eventualidad $y$ propio contexto, entre lo real y lo virtual. Ambas obras despliegan una temporalidad no lineal para hablar de la actualidad como gran fuerza política, pero sin hablar directamente de política.

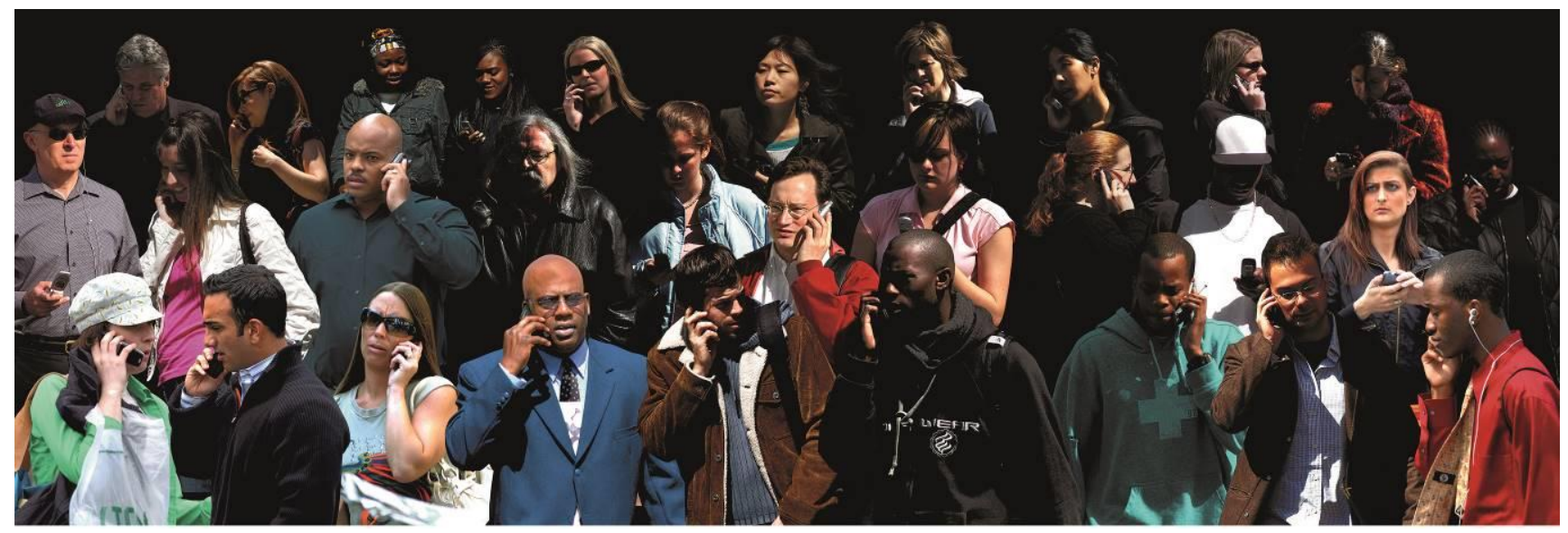

Figura 9: Fotografía cibachrome, metacrilato y madera. Fragmento de “Des-conectados III”, Jesús Segura, 2008. Tamaño: 130 x 390 cm. Serie de tres obras. Fotografía del autor.

\section{CONCLUSIONES}

Tras el análisis de las principales obras fotográficas y audiovisuales de Jesús Segura, podemos determinar que sus imágenes visuales son capaces de crear nuevas experiencias temporales cuando se cruzan en nuestro camino. Un tiempo que fluye a distintas velocidades y en distintas direcciones. Que genera un movimiento atravesado por saltos, retardos, variaciones y discontinuidades, y que por ello pueden ser incluyas en la categoría de espacialidades desbordadas. Segura busca conseguir que el espectador se plantee su lugar en el mundo, que piense sobre cómo afectamos a los espacios como consecuencia del capitalismo multinacional y la globalización, que se cuestione el ritmo frenético y constante marcado por la visión socioeconómica y política eurocéntrica al retratar la red de interconexiones e interdependencias existentes dentro del sistema económico y social contemporáneo, y las consecuencias que tiene todo ello en nuestra vida diaria.

Sus imágenes no necesitan moverse para modificar nuestro sentido del tiempo; todas ellas, móviles y fijas, participan en el desarrollo de la temporalidad compleja que está en la base de una nueva historia del arte. Una obra con gran peso conceptual, teórico y crítico, pero que a su vez está provista de un impactante componente estético y visual que genera imágenes que son capaces de transformar la conciencia de nuestra espacialidad y contexto. Para Mieke Bal (2016) las imágenes de Jesús Segura actúan por tanto como interlocutoras en el presente más que como representaciones del pasado, como elementos activos que disuelven la rigidez aparente de las teorías establecidas sobre el espacio tiempo.

\section{FUENTES REFERENCIALES}

Bal, M. (2011). Heterochrony in the Act: The Migratory Politics of Time. En M. Bal y M.A. Hernández-Navarro (Eds.), Art and Visibility in Migratory Culture: Conflict, Resistance, and Agency (pp. 209-237). Amsterdam: Rodopi.

Bal, M. (2016). Tiempos trastornados. Análisis, historias y políticas de la mirada. Colección Estudios visuales. Madrid: Ediciones Akal.

Hernández-Navarro, M.A. (2014). Desvelar la tradición. Heterocronía y posmedialidad en Background Story de Xu Bing. Imafronte, 23. 187-205.

Mira, E. (2018). (De)construir escenas, tiempos y otras ficciones. En J. Segura, Time Lag (pp. 87-102). Murcia: Editorial Tres Fronteras.

Moxey, K. (2013). Visual Time. The image in History. Durham \& London: Duke University Press, p. 1. 
Segura-Cabañero, J. (2013). Critical Temporalities: The Case of Douglas Gordon. Arte, Individuo y Sociedad, 26(1), 54-66.

Segura-Cabañero, J. (2018). Contemporaneidades anacrónicas versus heterocronías temporales. Revista Contranarrativas, 1, 3-6.

Segura-Cabañero, J. y Simó-Mulet, T. (2017). Espacialidades desbordadas. Arte, individuo y sociedad, 29(2), 219-234.

Spivak, G. C. (1998). ¿Puede hablar el sujeto subalterno? Orbis Tertius, 3(6), 175-235. En Memoria Académica. Disponible en: http://www.fuentesmemoria.fahce.unlp.edu.ar/art revistas/pr.2732/pr.2732.pdf 